\title{
THE PERSPECTIVES OF CLINICIANS ON ENRICHING PATIENT EXPERIENCES IN A CLINICAL CONTEXT: A QUALITATIVE STUDY
}

\author{
Abela, Edward; \\ Farrugia, Philip; \\ Gauci, Maria Victoria; \\ Balzan, Emanuel; \\ Vella, Pierre; \\ Cassar, Glenn \\ University of Malta
}

\begin{abstract}
Understanding the viewpoint of clinicians in a healthcare setting is a vital task to comprehend the success of patients undergoing physical rehabilitation. Addressing user experience is an essential activity which designers undertake when formulating product specifications at the early stages of product design. The involvement of clinicians during the product use-phase influences the progress and achievements attained by the patients throughout their rehabilitation journey. Several clinicians $(n=16)$ were asked to participate in a qualitative study to evaluate the performance of different personae in activities of daily living. The experiences of patients who use rehabilitation products as part of their therapy session at the clinic were evaluated. Based on this evaluation, a set of clinician requirements were formulated to reflect the overall experience when using rehabilitation products. Understanding these requirements brought about several implications to be considered during the design cycle. Through these considerations and by adopting a user-centred design approach, designers are in a better position to design innovative products targeted at providing a high-quality user experience which increases customer satisfaction.
\end{abstract}

Keywords: User centred design, Requirements, Experience design, Rehabilitation

Contact:

Abela, Edward

University of Malta

Department of Industrial \& Manufacturing Engineering

Malta

edward.abela@um.edu.mt

Cite this article: Abela, E., Farrugia, P., Gauci, M. V., Balzan, E., Vella, P., Cassar, G. (2021) 'The Perspectives of Clinicians on Enriching Patient Experiences in a Clinical Context: A Qualitative Study', in Proceedings of the International Conference on Engineering Design (ICED21), Gothenburg, Sweden, 16-20 August 2021. DOI:10.1017/ pds.2021.567 


\section{INTRODUCTION}

Exploring the myriad of opportunities in promoting participatory design and understanding patient experiences has been a major focus in medical literature and rehabilitation product design in recent years. Various studies show that users prefer products which provide a positive user experience (UX), which in turn promotes better product bonding and long-term product use (Krueger et al., 2020). In physical rehabilitation, this entails a thorough design for experience (DFE) exercise, aimed at enriching patient experiences and product engagement. However, efforts in exploiting the centrality of patient-therapist interaction (PTI) from the perspective of clinicians, has been minimal (Peiris et al., 2012). The occupational working context of clinicians and day-to-day patient management have a direct influence on the rehabilitation journey of their patients. The fundamentality of the UX factor ties in directly with the design stage of a rehabilitation product. In view of a product, UX is often designated as "how well people understand it, how they feel about it while they are using it, how well it serves its purpose, and how well it fits into the context in which they are using it" (Bate and Robert, 2006). This correlates directly with the users of the product, including both the patients and clinicians in rehabilitation.

This study will exploit the understanding of UX from the perspective of clinicians in view of their patients during therapeutic physical rehabilitation. The clinician is regarded as an intermediate-user whilst the patient is regarded as an end-user of the product. In establishing and enriching the concept of PTI both actors are denoted as users of the therapeutic product used. Product designers are typically responsible to set direction in product management and are normally regarded as the innovators in UX design. Modern computer-aided engineering (CAE) design systems typically involve an input of user requirements with an output corresponding to iterative design techniques which meet certain constraints, such as with the generative design method shown in Figure 1(a). In this case, together with clinicians and patients, the designer is also regarded as a user of the product, as illustrated in Figure 1(b). In this regard, the basis of high-quality user experience (HQUX) involves a collaboration of the three discrete users, namely, the clinician, the designer, and the patient, through which UX can be enriched through participatory design principles and collaborative design platforms.

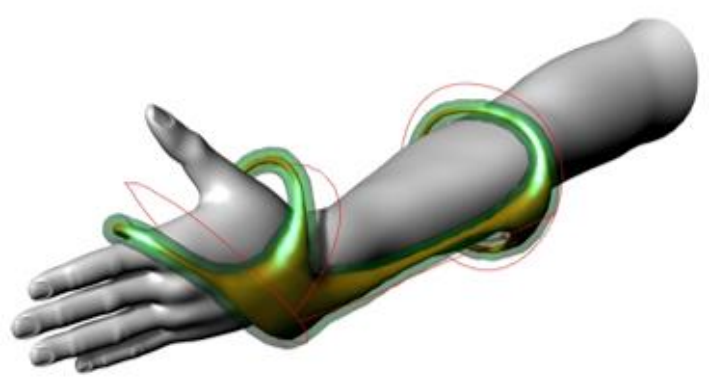

(a)

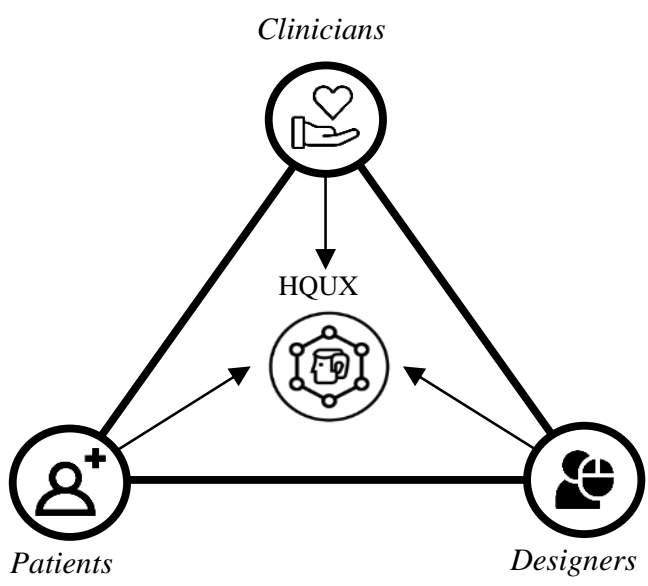

(b)

Figure 1. (a) Generative design method applied to the upper limb anatomy; (b) A triangulation of actors contributing towards high-quality UX (HQUX).

The main scope of this study is to focus on the clinician as a primary user and facilitator of the product at the level of the patient. In view of this triad of actors contributing towards UX, the paper will aim to answer the research question "Which aspects of $U X$ do clinicians value in rehabilitation product design, and how are these interpreted in a clinical setting?" The rest of this paper is structured as follows: Section 2 provides a general overview of patient experiences and work related to this study. Section 3 presents the methodology adopted to understand the perspectives of different therapists and identify a set of clinician requirements whilst Section 4 presents the results of the evaluation conducted in this study. Section 5 discusses the results and Section 6 draws the conclusions from the study. 


\section{DESIGNING PATIENT EXPERIENCES}

It has been reported that patients adopting early use of rehabilitation products in their recovery journey enjoy a better quality of life in the later stages of their recovery process (Scherer and Cushman, 2001). This is achieved by addressing product usability and UX, which is the current focus in the field of medical device design (Bitkina et al., 2020). This study was conducted in the early design stages of a bespoke and innovative hand-held controller for personal rehabilitation in a multi-user Virtual-Reality (VR) environment. It explores the possibility of "designing experiences", rather than designing products or services. This will be achieved by formulating a set of clinician requirements in view of rehabilitation products used in their clinic by their respective patients.

\section{Clinical User Experience}

The International Organisation for Standardisation (ISO) defines UX as: "The user's perceptions and responses that result from the use and/or anticipated use of a system, product, or service" (ISO 9241210:2019). In this study, the above definition is assumed. The terms perceptions and responses refer to the users' emotions, beliefs, preferences, perceptions, comfort, behaviours, and accomplishments that occur before, during and after using the product (ISO 9241-210:2019). Different researchers have adopted this definition to scrutinise the variance amid different notions in industrial design. Brade et al. (2017) specifically described the concept of UX in view of VR devices as a combination of product usability and aesthetics, attractiveness, and joy-of-use. This category of target devices is relevant to this study since the investigation forms part of a wider research project aimed at understanding the opportunities in exploring product design for rehabilitation within VR environments. In conjunction with the definitions adopted by ISO, it is understood that UX is also a consequence of the product's performance, functionality, interactive behaviour, and assistive capabilities. In this case, UX is also a product of the user's attitudes, past experiences, personality, skills, and abilities, together with the usecontext of the product (ISO 9241-210:2019). The study seeks to understand the perceptions of clinicians on enhancing UX during task clarification, through formulating a set of requirements with the clinician as the main facilitator of the therapy. In formulating these requirements, the aim is to address the first part of the hypothesis which states that "through formulating a set of clinician requirements into a user-centred design framework, designers would be in a better position to develop HQUX rehabilitation products". Occupational and physiotherapists, among other clinicians are fundamental in contributing towards the rehabilitation of individuals with a wide range of impairments such as musculoskeletal injuries and stroke. Assistive devices and rehabilitation products can transform therapy sessions into engaging and appealing activities for individuals who acquire these disabilities (Perera et al., 2018). It is therefore significantly important to obtain feedback from clinicians to understand patient experiences during the session and during product use. This activity also supports the idea of "need-finding" to identify user requirements and hence visualise idea concepts in the early design stage.

\section{Related Work on User Experience}

Although very limited in number, several works have investigated both the experiences of patients and clinicians during therapy. In their study, O'Keeffe et al. (2016) reviewed different factors which influence PTI during therapy. Through a thematic analysis the authors highlighted the relevance of the clinician's interpersonal, communicative and practical skills, individualised treatment and other environmental factors during therapy. Several elements were deemed central to PTI, such as listening, empathy, friendliness, encouragement, confidence, time and flexibility with patient appointments. These aspects were also explored in other studies such as the ones by Visch et al. (2011) and Chitturi (2009). However, these studies do not address the element of UX during assistive product use, and they raise no implications to product design in the form of clinical requirements. Morera-Balaguer et al. (2018) studied the clinicians' experiences and perceptions concerning the barriers and facilitators of therapy. The patient-therapist relationship during therapy was shown to be dependent on the patient's attitude and the clinicians' skills and experience. Similar conclusions have been made in the study by Pinto et al. (2012). On the other hand, the practice of multidisciplinary and participatory design approaches is observed to improve product design activities, particularly in the development of assistive and rehabilitation products. This is observed in numerous studies such as the ones by Perera et al. (2018), Allsop et al. (2010), Gunatillaka (2009) and Bridgelal et al. (2008). In particular, Perera et al. (2018) studied different ways how design methodologies can be adopted in assistive product 
development used in the rehabilitation of children with disabilities. Several considerations regarding co-design and product properties were made in order to develop a set of therapy assistive products aimed at improving upper limb dexterity of children with CP. It was observed that therapeutic functions like movement types, patterns, ergonomics, and postural capabilities of users influence product design. Nonetheless, the study by Perera et al. (2018) focuses on establishing a quality therapeutic relationship through the product but does not address issues raised through product design. This leaves a gap between clinical requirements and product design implications.

This literature review shows that designers need a set of requirements which allows them to design products of higher quality of experience. It is observed that clinical requirements and product design implications are equally important to the patient but are often tackled independently, not simultaneously. This study will exploit the understanding of UX from the perspective of the clinician working in the clinic. It will also seek to provide a comprehensive understanding of design considerations for products used in rehabilitation following the feedback of clinicians and their perceptions on patients' experiences.

\section{METHODOLOGY}

\section{Data Collection}

A total of 16 clinicians were interviewed individually with the aim of establishing the principal characteristics which define PTI, gathering information about existing in-house products, and obtaining feedback from clinicians during therapy. These goals facilitate the identification of potential opportunities in designing products which deliver an increased quality of experience during use. A semi-structured interview was conducted in order to obtain qualitative information about the clinicians and their patients. The selected qualitative approach sought to interpret the commonalities among clinicians in view of patient UX. Open discussions were held in order to describe the typical experiences of patients on a day-to-day basis when visiting the clinic. All interviews were conducted by one researcher through an interview script and a set of questions were constructed. Questions were asked regarding the clinicians' occupation, experience, and their general outlook on patient experiences in their clinic. Key questions included the following: "In what ways do you think that understanding your client's ergonomic and biomechanical requirements is important?"; "To what extent do you think emotional experiences affect the patient's rehabilitation?"; "Do you think that providing bespoke products to your clients improves their rehabilitation?" The questions were orally presented to each participant and the interviews were taperecorded and transcribed verbatim. Interviews lasted an average of 60 minutes. Consequently, a set of codes were assigned to different phrases within the transcripts whilst consistent codes were grouped into categories which facilitated the formulation of a set of core themes as part of the thematic analysis described in Section 4. The thematic analysis was based on the guidelines proposed by Braun and Clarke (2006). In addition, an Inter-Rater Reliability (IRR) factor was generated in order to assess both the consistency and the replicability of the performed qualitative analysis. A pilot study was carried out with two researchers to reduce the bias factor of data collection and to review the layout and presentation of the semi-structured interview. The necessary improvements in wording, terminology and layout structure were implemented accordingly.

\section{Participants}

A total of 16 participants were recruited from 5 healthcare institutions and 1 academic institution. In no particular order, the institutions are the following: Global Disability Innovation Hub (UK), National Institute for Health Research (UK), St James Capua Hospital (Malta), Mater Dei Hospital (Malta), NICOMED Rehabilitation Centre (Cyprus), and the University of Malta (Malta). Participant occupation and experience varied among clinicians. Three of the interviews were conducted face-to-face at the participant's clinic, whilst the remaining interviews were conducted remotely, both due to a number of participants being located internationally, and also as a result of the COVID-19 pandemic at the time of conducting the study. The majority of participants had over 20 years of experience (43\% of respondents), whilst $25 \%$ had between 10 and 15 years of experience, and 32\% of participants had less than 5 years of experience (Mean=12.8 years, $S D=6.8$ years). $75 \%$ of the participants were female and only $25 \%$ were male. Table 1 shows a description of the participants in this study. 
Table 1. List of participants in this study

\begin{tabular}{ccr}
\hline Ref. & Occupation & Institution \\
\hline$P 1$ & Occupational Therapist, Lecturer & University of Malta \\
\hline$P 3$ & Rehabilitation Centre Manager & NICOMED Rehabilitation Centre \\
$P 8$ & Physiotherapist & National Institute for Health Research \\
\hline$P 5$ & Clinical Scientist \& Research Fellow & \\
\hline$P 4$ & Trainee Clinical Scientist & \\
$P 6$ & Engineer, Assistive Technology Researcher & \\
$P 7$ & Occupational Therapist & \\
\hline$P 2$ & Senior Physiotherapist, Manager & \\
$P 9$ & Sports Physiotherapist & \\
$P 10$ & Physiotherapist Trainee & Mater Dei Hospital Hub \\
P11 & Physiotherapist Trainee & \\
\hline$P 12$ & Physiotherapist & \\
$P 13$ & Physiotherapist & \\
$P 14$ & Physiotherapist & \\
$P 15$ & Physiotherapist & \\
\hline
\end{tabular}

\section{IDENTIFIED CLINICIAN REQUIREMENTS}

A set of requirements were identified, which address the clinician in a user centred design (UCD) approach. The requirements (labelled as $R 1, R 2, R 3, R 4, R 5$ and $R 6$ ) have been established after the thematic analysis was performed on the information examined in the transcripts. Several factors which contribute towards the definition of UX and towards its enrichment were outlined (Figure 2). Primarily, the aspect of motivation was the factor with the highest number of references (statements) by respondents in the entire study (12.3\% contribution towards $U X)$. This was followed by Emotions (10.5\% contribution), Patient-Therapist Interaction (9.6\%), Engagement (7.0\%), Rehabilitation Progress (7.0\%), and Biomechanics (Range of Motion (ROM), forces) (6.1\%).

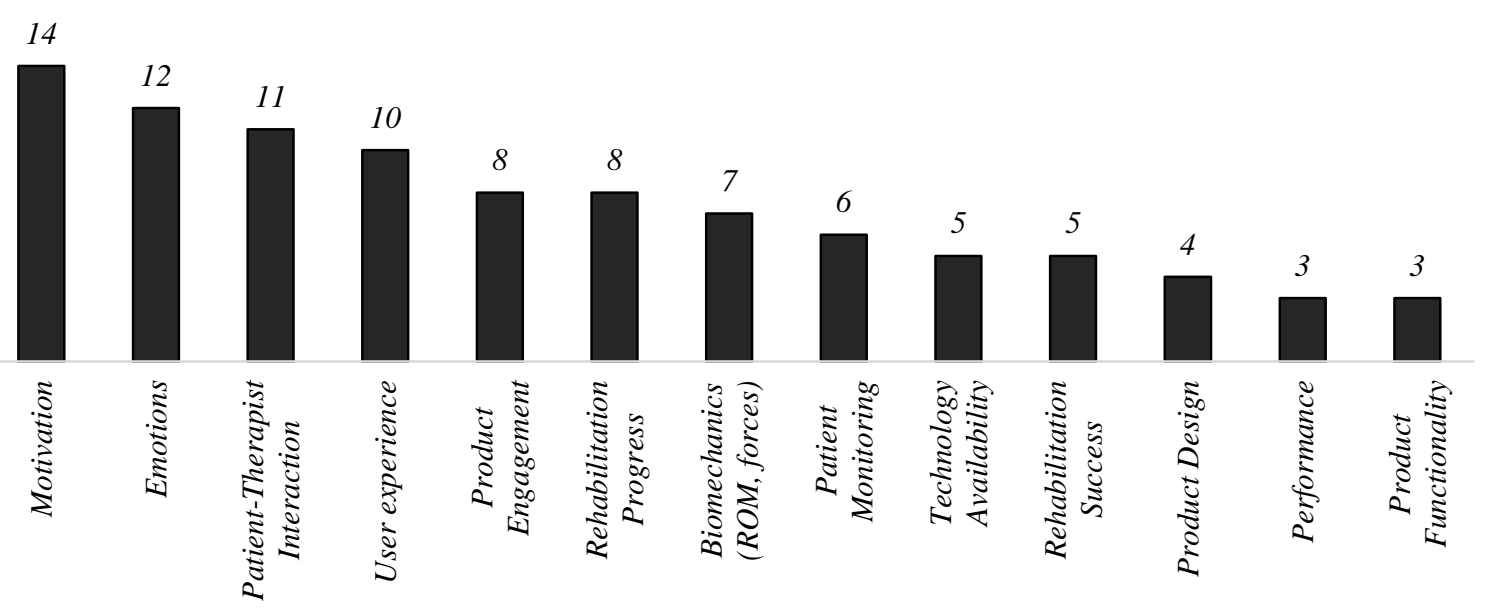

Figure 2. The total number of statements with different factors mentioned in all interview data.

\section{R1. The Importance of Motivation During Therapy}

Motivation is directly influenced by the emotional level of the individual. As shown in the work of Maclean and Pound (2000), a lack of motivation results in patients less likely to engage in therapy sessions. The study showed that therapists normally interact with patients having conditions such as depression, who do not see any hope for a better future, are neither willing to perform exercises properly, nor use rehabilitation products. In this case, the clinician is expected to show empathy, encouragement, and motivation. Clinician $P 1$ indicated that patients with past negative experiences in using rehabilitation devices will avoid using other products in their therapy sessions. Thus, high motivation implies better engagement with the therapy and therefore improved outcomes in rehabilitation. It was shown that 
custom devices enhance the motivation of patients, arising from increased engagement with products designed particularly for them (25\% of respondents). Designers address this requirement through the design of bespoke technology whereby this acts to increase the motivational level of patients during therapy. Designing attractive and theme-based products to the likings, requests or hobbies of the patients also increases the patient's motivation. The clinicians' feedback during the design stage of a particular product is an influential factor which supports the decision-making activities of the designer. With this feedback, the designer is better equipped to address the preferences, needs and expectations of the patients and to design products which motivate them in increasing their rehabilitation success.

\section{R2. The Influence of Patient Satisfaction in Rehabilitation}

The study has shown an increased clinical awareness towards promoting patient satisfaction during therapy sessions. $94 \%$ of respondents believe that introducing new products during therapy leads to a more engaging experience to their customers. In addition, $31 \%$ of respondents believe that the process of prescribing conventional physical exercises becomes routinely tedious and monotonous overtime. However, clinicians believe that improving patient satisfaction is a highly subjective activity (63\% of respondents). Upon combining rehabilitation products with therapy, patient satisfaction was observed to increase, particularly with children (25\% of respondents). The study also showed that patients are occasionally scared of trying out new products due to insecurity, a lack of self-confidence or mental health issues, such as anxiety. Considering product design activities, P6 remarked that "Involving the patient in decision making about design and functional features of certain products could be very attractive." Through implementing a participatory design approach, patients may be involved in the design of product ergonomics, texture, colour and style. A total of $25 \%$ of respondents emphasised the importance of designing custom devices to increase satisfaction. Customisation activities are possible during the design of rehabilitation devices (such as hand-held controllers), the design of games and virtual environments and the customisability of 3D printed products.

\section{R3. An Understanding of Ergonomics and Biomechanics}

Clinicians understand that good product ergonomics and biomechanics are vastly important in any rehabilitation product (94\% of respondents). P5 commented that designers should design products which are safe because clinicians are always concerned about the human interaction with external systems or products which claim to optimise the patient's performance. $P 5$ also said that in a routine clinical assessment, a patient may be diagnosed with a functional problem at a specific part of the body, however upon ergonomic and biomechanical assessment, it becomes evident that other regions of the body are also affected. Clinicians must therefore understand the ergonomic and biomechanical requirements of their patients, and support in the design of products which are ergonomic and nonharmful. To ensure this, product structure is based on patient anatomy, anthropometric data and force measurements obtained by the clinicians. The final products should not trigger any pain during its use. Designers are also encouraged to consider the impact of product design on users with disabilities.

\section{R4. Objective Monitoring of Patients}

Patient management involves the assessment of functional improvement in the patient's rehabilitation journey. This study showed that there is currently a lack of computer-based tools in industry which specifically monitor the progress of patients during therapy ( $88 \%$ of respondents). In a clinical setting, this is still typically done manually. Clinicians understand that presently there is a need to design products which monitor the individual's biomechanics (such as measuring range of motion, endurance or muscle forces and strength). $P 3$ remarked that the higher the frequency of monitoring the better the rehabilitation outcomes of the patients will be. Designers are therefore encouraged to address the patient's progress through the product functionality. This is achieved through visual representations of the current progress, different operational levels and visual scoring. Upon monitoring the patient's performance, the rehabilitation device may need to be modified, depending on the stage of the therapy, to reflect the current progress of the individual. Through an adequate monitoring platform, the clinician evaluates the functionality and reactions of the patient when using the product. This presents an opportunity to the clinician to address the patient's feedback and improve their experience when using the product. Based on objective monitoring of patients, clinicians may then provide feedback to the designer to elaborate the product architecture accordingly, by changing particular components, or other functional elements. This will support the designer in delivering products which address the specific needs of each patient. Objective monitoring is also accomplished through VR environments. The integration of VR systems was often regarded as an opportunity in a clinical setting ( $81 \%$ of respondents). 


\section{R5. The Influence of Emotional Experiences in Rehabilitation}

Interpreting emotions and translating them into product specifications is a central task in product design. All clinicians agreed that emotions play a major role in determining therapeutic success. The emotional status of the patient should always be primarily assessed, as this may hinder the overall recovery process. Some patients may be at risk of anxiety, depression, or panic disorders (Zurowski et al., 2013), which has a direct influence on usability and UX. P5 remarked that some patients often experience both performance and clinical anxiety during therapy sessions. This results in feelings of nervousness, restlessness, tension, a sense of danger or panic, and symptoms such as an increased heart rate and hyperventilation. Adopting principles of emotional design at the early design stages contributes towards understanding patient emotions and the transition from one to another. The visual and aesthetic design together with form and style interest the patient doing therapy. In particular, Pl commented that the purpose of functional design in this aspect is to give the opportunity to patients to own unique products which they are excited to use and proud to be seen using. Designers are encouraged to create products which deliver positive experiences to the patient. An effort should be made during conceptualisation to address usability and design products which are understandable, easily explained, and highly intuitive. As a result, these trigger positive emotions in the patient undergoing therapy. Rehabilitation success is also vastly dependent on the patient's will during recovery (38\% of respondents). To address this factor, clinicians should be supportive of building the proper rehabilitation plan with their patients and offer support in converting negative emotions (such as sadness and fear) into positive ones (such as happiness and joy). High-quality UX is the result of a holistic PTI, and a consideration of the elements of trust, support, apathy level, mood, emotional support, and psychosocial aspects. These elements can only be fulfilled through meeting fundamental needs like product functionality and reliability. Designers focus on providing consistent products across all uses, in accordance with the personality type and characteristics of the patient. Products with consistent buttons, colours, switches, and icons, and without unnecessary functions and features are easier to use. Product variants and customisation to the patient's desires, age and gender, contribute towards inducing positive emotions during the use-phase.

\section{R6. Use of Emerging Technology for Rehabilitation}

This study has shown that adopting rehabilitation products at the clinic in conjunction with the existing therapy methods is generally both helpful and desirable (94\% of respondents). Patient expectations in view of new rehabilitation products, is primarily dependent on age and likings, product affordability and ease-of-use. Nevertheless, it was clear that technology is not always readily accessible to all patients. P5 commented that children with dystonia often feel disregarded due to assistive products requiring a high level of dexterity and skill. Through integrating bespoke technology with digital environments (such as VR), designers are in a better position to provide patients with the opportunity to participate in serious gaming activities which motivate patients towards reaching their desired outcomes and a better quality of treatment. Clinicians regard such technology as an opportunity to offer the prospect of incorporating different environments associated with the patient's preferences or hobbies, such as playing tennis, handball, or painting. Products may involve an element of gamification of the therapeutic exercise which introduces elements of competitiveness and scoring. Modular product architecture contributes towards addressing the different activities mentioned above. The designer is then able to classify rehabilitation products into different categories based on product structure and architecture. This provides the possibility to reuse components in multiple rehabilitation products, which saves both time and cost in development.

\section{DISCUSSION OF EMERGING THEMES}

The qualitative approach adopted in this paper made it possible to address the research question of what enriches high-quality UX from the perspective of rehabilitation clinicians. This was achieved through identifying a set of clinician requirements $(R l$ to $R \sigma)$ in view of their patients undergoing physical rehabilitation. When this process is iterated with different stakeholders, particularly with the patient and the designer (who complement the triangulation of actors in Figure 1), it leads to the formulation of a design framework aimed at providing a high-quality UX within the area of rehabilitation product design. The findings in this study confirm that addressing patient needs is an indispensable step to enhance the PTI, patient participation, and to contribute to the satisfaction of patients, as seen in the studies by Zanini et al. (2014), Edwards et al. (2009) and Heritage et al. (2006). 
The selected methodology was highly suited in providing a thorough understanding of the patient's experiences, emotions, and level of satisfaction upon integrating rehabilitation products as part of the therapy. This ultimately supports designers to provide an enriching experience through design. It is shown that UX is not limited to product design but is heavily influenced by the general outlook on the service provided to the patient and their motivation (Requirement 1). In this regard, patients with mood disorders, such as depression or anxiety disorders expect more than a product which supports their functional rehabilitation (Requirement 2). It can therefore be argued that anything which promotes independence and makes the life of the patients better, is a contributor towards high-quality UX, as observed in the study conducted by Wilkinson, C. (2016). The importance of approaching the patients with empathy towards their emotions from the moment they first step in the clinic is therefore stressed. The element of participatory design was found to have a major influence on UX, since involving patients in design ensures that their needs and requirements are met. Moreover, it was clear that a good understanding of ergonomics and biomechanics prevents further health complications and joint deformities whilst ensuring a safe environment to operate within (Requirement 3). These considerations exploit the patient's rehabilitation outcomes such that a higher level of functionality can be sought in order to improve the patient's quality of life, in conjunction with an adequate prescription of physical exercises. The regular monitoring of qualitative information is a challenging task because it is generally difficult to interpret the fluctuation in emotions since these vary from one patient to another. Clinicians are also in favour of introducing new technology (Requirement 5) in conjunction to existing conventional therapy, even though this may require additional resources including time, training, and funding. This was also observed in the study conducted by Braun et al. (2018). The incorporation of rehabilitation products in therapy sessions puts clinicians in a better position to monitor the patient's progress, whilst providing something to aim for with regards to their patients. The combination of therapy sessions with Virtual Reality, which was a popular choice in emerging technologies amongst clinicians (Requirement 6 ), was seen to address this problem because this provides an added benefit through simulating virtual settings without any environmental hazards. For instance, patients using VR do not fear stumbling or falling over, as they are aware of their surroundings and their safety. This does not necessarily imply an optimal solution for all patients as clinicians argue that patients react differently to virtual environments. For several patients, immersing in a VR environment would be an entirely new experience and is possibly anxiety-producing due to feeling trapped or claustrophobic (Tsai et al., 2018). It was clear that VR technology is generally looked upon with caution amongst the interviewed clinicians. The reason is that this often gives rise to multiple side effects in individuals with neurological disorders, such as with patients experiencing epileptic seizures or fits. These concerns have been raised in numerous studies concerning the use of VR in rehabilitation, however, in their studies, Tychsen et al. (2020) and Cortés-Pérez et al. (2020) argue that the medical literature is not supportive of the idea that VR poses a risk in children and adults with epilepsy or stroke. On the other hand, VR technology is consistently regarded as an exciting and emerging field in healthcare (Fertleman et al., 2018). Herein it is argued that VR provides an opportunity to the clinicians in enriching PTI and in providing their patients with effective therapy exercises combined with an aspect of fun and entertainment.

\section{Limitations and future work}

One limitation of the study is a small sample size (16 participants). In order to offset this limitation, it was ensured that a good mix of participants with various backgrounds and experience in rehabilitation were interviewed. A purely qualitative analysis can also be regarded as restrictive. However the selected approach did not impose the limitations of quantitative methods, such that clinicians could add context and expand on arguments which numbers alone would have been unable to reveal. Future work may use research methodologies that allow the direct involvement of patients in the design process. As cited in Hamzah and Wahid (2016), in participatory design it is crucial to involve patients and clinicians from an early stage in order to ensure that the developed product meets the specified requirements. To address the needs of different stakeholders, similar studies with patients and designers are planned. Based on the requirements highlighted in this paper, together with those identified in separate studies, a framework for a computer-based design assistance tool will be developed. This is aimed at supporting designers in generating bespoke device designs suited for the patient which render rehabilitation a high-quality experience. Future work may also explore the vast applications of Product-Service Systems (PSS) design methodologies in research projects which 
incorporate the needs of users when creating solutions that address user satisfaction, expectations and needs (Braga et al., 2020). Such design-oriented goals form the basis of Value Driven Design (VDD) processes (Bertoni et al., 2019, Ericson et al., 2007) which complement conventional design methodologies in engineering (Panarotto et al., 2017, Isaksson et al., 2013).

\section{CONCLUSION}

It is concluded that the main contribution of this paper lies in the identification of the requirements outlined from the qualitative study conducted with various clinicians in view of their patients undergoing rehabilitation in a clinical setting. The study has laid the foundation for the development of a design support framework which supports designers to design rehabilitation products, which offer a high-quality UX during therapy sessions. Additional studies are required to identify patient and designer requirements, which complement the developed clinician requirements proposed in this study.

\section{Acknowledgments}

This project has received funding from the European Union's Horizon 2020 research and innovation programme under grant agreement $\mathrm{N}^{\circ} 856998$ (PRIME-VR2).

\section{REFERENCES}

Allsop, M. J., Holt, R. J., Levesley, M. C. and Bhakta, B. (2010), “The engagement of children with disabilities in health-related technology design processes: Identifying methodology", Disability and Rehabilitation: Assistive Technology, Vol 5, No. 1, pp. 1-13, https://doi.org/10.3109/17483100903323267

Bate, P. and Robert G. (2006), "Experience Based Design: From Redesigning the System around the Patient to Codesigning Services with the Patient", Quality and Safety in Health Care, Vol. 15 No. 5, pp. 307-310, https://doi.org/10.1136/qshc.2005.016527

Bertoni, M., Bertoni, A. and Murat Hakki, E. (2019), "Value Driven Design Revisited: Emerging Modelling Concepts and Applications", Proceedings of The Design Society: International Conference on Engineering Design, Vol. 1, No. 1, pp. 2407-2416, https://doi.org/10.1017/ dsi.2019.247

Bitkina, O. V., Kim, H. K. and Park, J. (2020), "Usability and user experience of medical devices: An overview of the current state, analysis methodologies, and future challenges", International Journal of Industrial Ergonomics, Vol. 76, https://doi.org/10.1016/j.ergon.2020.102932

Brade, J., Lorenz, M., Busch, M., Hammer, N., Tscheligi, M. and Klimant, P. (2017). "Being there again Presence in real and virtual environments and its relation to usability and user experience using a mobile navigation task", International Journal of Human-Computer Studies, Vol. 101, pp. 76-87, https://doi.org/10.1016/j.ijhcs.2017.01.004

Braga, A., Toledo, J., \& González, M. (2020), "Systematized methods for the development of Product-Service Systems: a systematic literature review", Product Management \& Development, Vol. 18, No., pp. 3-18, https://doi.org/10.4322/pmd.2019.017

Braun T., Rieckmann A., Weber F. and Gruneber C. (2018), "Current use of measurement instruments by physiotherapists working in Germany: a cross-sectional online survey", BMC Health Services Research, Vol. 18, No. 810, https://doi.org/10.1186/s12913-018-3563-2

Braun, V. and Clarke, V., (2006). "Using thematic analysis in psychology", Qualitative Research in Psychology, Vol. 3, pp. 77-101, https://doi.org/10.1191/1478088706qp063oa.

Bridgelal Ram, M., Grocott, P. R. and Weir, H. C. M. (2008), "Issues and challenges of involving users in medical device development", Health Expectations: An International Journal of Public Participation in Health Care and Health Policy, Vol. 11, No. 1, pp. 63-71. https://doi.org/10.1111/ j.1369- 7625.2007.00464.x

Chitturi, Ravindra (2009). "Emotions by design: A consumer perspective", International Journal of Design, Vol. 3, No. 2, pp. 7-17

Cortés-Pérez, I., Nieto-Escamez, F. A. and Obrero-Gaitán, E. (2020). "Immersive Virtual Reality in Stroke Patients as a New Approach for Reducing Postural Disabilities and Falls Risk: A Case Series", Brain sciences, Vol. 10, No. 5, pp. 296, https://doi.org/10.3390/brainsci10050296

Edwards, A., and Elwyn, G., (2009), "Shared Decision-Making in Health Care: Achieving Evidence-Based Patient Choice", Oxford University Press, New York, NY, USA.

Ericson, A., Larsson, A., Larsson, T. and Larsson, M. (2007). "Need Driven Product Development In Teambased Projects", International Conference on Engineering Design, Luleå University of Technology, Sweden

Fertleman, C., Aubugeau-Williams, P., Sher, C., Lim, A. N., Lumley, S., Delacroix, S. and Pan, X. (2018), “A Discussion of Virtual Reality as a New Tool for Training Healthcare Professionals", Frontiers in Health, Vol. 6, https://doi.org/10.3389/fpubh.2018.00044 
Gunatillaka, K. A. N. (2009), "Cerebral palsy - Understanding the disabilities and planning intervention”, Sri Lanka Journal of Child Health, Vol. 33, pp. 46-51, https://doi.org/10.4038/ sljch.v33i2.652

Hamzah, A. and Wahid, F. (2016), Participatory Design in the Development of Healthcare Systems: A Literature Review, Proceedings of the 2nd International Conference on Communication and Information Processing, https://doi.org/10.1145/3018009.3018010

Heritage, J., and Maynard, D. W. (2006), "Communication in Medical Care: Interaction between Primary Care Physicians and Patients”, Cambridge University Press, Cambridge, UK

International Organization for Standardization, (2019), "Ergonomics of human-system interaction - Part 210: Human-centred design for interactive systems”, ISO 9241-210:2019, ISO, Geneva.

Isaksson, O., Kossmann, M., Bertoni, M., Eres, H., Monceaux, A. and Bertoni, A., Wiseall, S. and Zhang, X. (2014), "Value-Driven Design - A methodology to Link Expectations to Technical Requirements in the Extended Enterprise", International Council on Systems Engineering International Symposium, Vol. 23, No. 1, pp. 803-819, https://doi.org/10.1002/j.2334-5837.2013.tb03055.x

Krueger, A. E., Pollmann, K., Fronemann, N. and Foucault, B., (2020), “Guided User Research Methods for Experience Design - A New Approach to Focus Groups and Cultural Probes”, Multimodal Technologies and Interaction, Vol. 4, No. 3, pp. 43-65, https://doi.org/10.3390/mti4030043

Maclean, N and Pound, P. (2000). "A critical review of the concept of patient motivation in the literature on physical rehabilitation”, Social Science and Medicine, Vol. 50, No. 4, pp. 495-506, https://doi.org/10.1016/s0277-9536(99)00334-2

Morera-Balaguer, J., Botella-Rico, J. M., Martínez-Gonzáles, C., Medina-Mirapeix, F. and Rodriguez-Nogueira, Ó. (2018), "Physical Therapists' Perceptions and Experiences about Barriers and Facilitators of Therapeutic Patient-Centred Relationships during Outpatient Rehabilitation: A Qualitative Study." Brazilian Journal of Physical Therapy, Vol. 22, No. 6, pp. 484-492, https://doi.org/10.1016/j.bjpt.2018.04.003

O’Keeffe, M., Cullinane, P., Hurley, J., Leahy, I., Bunzli, S., O'Sullivan, P. B., O'Sullivan, K. (2016), “What Influences Patient-Therapist Interactions in Musculoskeletal Physical Therapy? Qualitative Systematic Review and Meta-Synthesis", Physical Therapy, Vol. 96, No. 5, pp. 609-622, https://doi.org/10.2522/ptj.20150240

Panarotto, M., Wall, J., Bertoni, M., Larsson, T. and Jonsson, P. (2017), "Value-driven simulation: Thinking together through simulation in early engineering design", 21 st International Conference on Engineering Design (ICED), Vancouver, The Design Society

Peiris, C. L., Taylor, N. F. and Shields, N. (2012), "Patients Value Patient-Therapist Interactions More than the Amount or Content of Therapy during Inpatient Rehabilitation: A Qualitative Study." Journal of Physiotherapy, Vol. 58, No. 4, pp. 261-268, https://doi.org/10.1016/s1836-9553(12)70128-5

Perera, G. and Ranasinghe, W. (2018), "Design Approach to Rehabilitation: Developing Therapy Assistive Products for Children with Hemiplegic Cerebral Palsy", International Journal of Architectural Research, Vol. 12 No. 2, pp. 307-318, https://doi.org/10.26687/archnet-ijar.v12i2.1528

Pinto, R. Z., Ferreira, M., Oliveira, V., Franco, M., Adams, R., Maher, C. and Ferreira, P. (2012). "Patientcentred communication is associated with positive therapeutic alliance: A systematic review ", Journal of physiotherapy, Vol. 58. pp.77-87, https://doi.org/10.1016/S1836-9553(12)70087-5

Scherer, M. and Cushman, L. (2001), "Measuring subjective quality of life following spinal cord injury: A validation study of the assistive technology device predisposition assessment", American Journal of Physical Medicine Rehabilitation, Vol. 23, pp. 387-393

Tsai, C. F., Yeh, S. C., Huang, Y., Wu, Z., Cui, J. and Zheng, L. (2018), “The Effect of Augmented Reality and Virtual Reality on Inducing Anxiety for Exposure Therapy: A Comparison Using Heart Rate Variability." Journal of Healthcare Engineering, Vol. 2018., https://doi.org/10.1155/2018/6357351

Tychsen, L. and Thio, L. (2020). "Concern of Photosensitive Seizures Evoked by 3D Video Displays or Virtual Reality Headsets in Children: Current Perspective”, Vol. 12, pp. 45-48, https://doi.org/10.2147/EB.S233195

Visch, V., Wit, M., Dinh, L., Brule, D., Melles, M. and Sonneveld, M. (2011). "Industrial Design meets mental healthcare: Designing products involving game-elements for mental healthcare therapy - Three case studies", 2011 IEEE 1st International Conference on Serious Games and Applications for Health, https://doi.org/10.1109/SeGAH.2011.6165457

Wilkinson, C. (2016), "User Centred Design Method for the Design of Assistive Switch Devices to Improve User Experience, Accessibility and Independence”, International Journal of Usability Studies, Vol. 11, pp. 66-82.

Zanini, C., Sarzi-Puttini, P., Atzeni, F., Di Franco, M., and Rubinelli, S. (2014), "Doctors' Insights into the Patient Perspective: A Qualitative Study in the Field of Chronic Pain", BioMed Research International, Vol. 2014, pp. 1-6, https://doi.org/10.1155/2014/514230

Zurowski, M., McDonald, M. W., Fox, S. and Marsh, L. (2013), "Psychiatric Comorbidities in Dystonia: Psychiatric Comorbidities in Dystonia: Emerging Concepts Concepts" Movement Disorders, Vol. 28, No. 7, pp. 914-920, https://doi.org/10.1002/mds.25501 